\title{
No Standard for Standards: Understanding the ICT Standards Development Ecosystem
}

There is no standard for standards. Technology standards are created, maintained and propagated in a bewildering variety of ways, by a diverse set of actors. This Chapter attempts to explain this ironic and complex reality, and to provide a framework for understanding different standards development models in the information and communications technology (ICT) industry.

Some examples can set the stage. LTE, the widely adopted current-generation wireless telecommunications standard, was developed under the aegis of 3GPP - an organization made up of several national and regional telecommunications standards bodies - in accordance with a framework defined by the International Telecommunications Union (ITU). USB, "the most successful computer interface ever" according the Economist magazine ${ }^{1}$, was defined and continues to be controlled by a handful of large technology companies operating under a contractual agreement, and is managed by the non-profit USB Implementers Forum. 12C, a ubiquitous chip-to-chip interface, was developed and championed by a single company, which now makes the specification freely available for third party download and adoption. The familiar $3.5 \mathrm{~mm}$ headphone jack evolved from technology used in the very earliest days of voice telephony, and current interoperability is largely based on custom and loose consensus among manufacturers.

One approach to this diversity and complexity might be to define it away. That is, we could say that "standards" are those particular technical specifications developed by a certain set of large, well-established standards organizations (such as the ITU in our examples above), and that everything else are "industry specifications," or "de facto standards" or have some other status that is secondary to the standards produced by certain prominent organizations. This approach would paint an incomplete picture of how interoperability works in the information and communications technology industry, however: as discussed further below, large formal standards organizations such as the ITU are important for ICT standardization, but evidence suggests that they may no more important than other key actors in the complex drama of ICT standard setting. Accordingly, the approach of this Chapter is to adopt a broad and inclusive definition of standards that sweeps in a wide variety of approaches to ICT interoperability. For our purposes, LTE, USB, I2C and the $3.5 \mathrm{~mm}$ headphone jack-and all similar technical specifications that enable ICT products and services owned or controlled by different parties to interoperate-are all "standards."

This Chapter describes a taxonomy for the ICT standards setting ecosystem that is based on the identity of the standards developer. The Chapter also briefly describes an overlapping, sometimes contentious framework that analyzes the standards development process and

\footnotetext{
${ }^{1}$ In praise of the humble USB, http://www.economist.com/blogs/babbage/2014/07/differenceengine- 0
} 
applicable intellectual property rules, usually in an effort to determine whether a specification could or should be deemed an "open standard."

After sketching out a taxonomical framework, the Chapter draws from some empirical research to demonstrate the great diversity of approaches to standards development that manifest in technology products. This research shows that non-traditional standards development models play critical role in ICT standardization, to a degree that may surprise standards professionals and policymakers steeped in the traditional standards development system. Further, the research demonstrates another potential surprise: while policymakers and others understandably express preferences for open standards, ICT standardization is frequently not "open" (under various definitions of the term). The Chapter concludes by noting that the ICT standardization ecosystem now appears to be in the midst of significant changes, largely driven by the collision of traditional ICT interoperability specification development processes with the world of open source software-adding additional intricacy to an already complex system.

\section{A taxonomy of standards setting organizations.}

The taxonomy of standards setting organizations described here builds on work initially outlined in a 2009 white paper published by the Intellectual Property Owners Association ${ }^{2}$ and expanded in some 2012 work published by this Chapter's author and several co-authors. ${ }^{3}$ In brief, the framework is as follows:

- Standards Setting Organizations (SSOs) are an inclusive superset of formal SDOs and consortia.

- Formal Standards Development Organizations (SDOs) are standards developers that are formally recognized by some government authority. This recognition can be straightforward, as in the case of national standards bodies. It can flow upstream-e.g., national governments recognize the authority of international bodies like the ITU. It can also be attenuated: for example, the U.S. government recognizes the private non-profit American National Standards Institute (ANSI) as the body that coordinates U.S. national standards, and ANSI in turn accredits numerous private sector-led standards development organizations, all of which are considered formal SDOs.

- Formal SDOs come in a variety of flavors:

2 Intell. Prop. Owners Assoc. Standards Setting Comm., Intell. Prop. Owners Ass'n, Standards Primer: An Overview of Standards Setting Bodies and Patent-Related Issues that Arise in the Context of Standard Setting Activities 3-9 (2009), available at http://www.ipo.org/AM/Template.cfm?Section=Search\&section=Standards_Setting_Webinar_ 10_21_09\&template=/CM/ContentDisplay.cfm\&ContentFileID=61348

3 Jurimetrics 
○ The Geneva-based "big three" international SDOs: the International Organization for Standardization (ISO), the International Electrotechnical Commission (IEC), and the International Telecommunication Union (ITU). A joint technical committee of ISO and IEC called JTC-1 is of sufficient importance to the ICT industry and operates with such a high degree of independence that it is sometimes considered separately, making a "big four" group of international SDOs. Subject to some significant caveats, governance in these organizations is generally driven by a one-country-one-vote model.

- Regional bodies, such as the European Committee for Standardization (CEN) or the Pacific Area Standards Congress (PASC), empowered by their national government constituents with creating regional standards.

- Government-led national standards bodies, such as the Bureau of Indian Standards (BIS) or Deutsches Institut für Normung (DIN), which set national standards.

- Large membership-driven SDOs with substantial global presence and membership. Examples include the IEEE, ASTM International, and the Society of Automotive Engineers. Governance in these organizations typically follows a one-member-one-vote model, with membership relatively open (in contrast to the country-oriented governance of the big three).

- Other, smaller and more specialized membership-driven SDOs, that differ from (e.g.) IEEE or ASTM only by a matter of degree. ANSI alone accredits nearly 300 such organizations. ANSI-accredited standards developers are required to abide by various rules promulgated by ANSI, including rules focused on openness of the standards development process, and decision-making due process.

- Consortia, also sometimes called Fora or Special Interest Groups (SIGs), are private sector-led organizations that create or otherwise support standards, but that are not formally recognized by a government authority as a standards developer.

- Consortia fall into two broad categories: incorporated consortia and contractual consortia. Incorporated consortia are distinct legal entities, typically formed by a collection of interested companies and funded by such companies. Most incorporated consortia are formed as non-profit trade associations (typically U.S.-based " 501 (c)(6)" organizations, for those familiar with the relevant provisions of U.S. tax code, with some Swiss-incorporated examples existing too), but a few are formed as charitable non-profits (generally U.S. " 501 (c)(3)" organizations, or occasionally charitable foundations formed under German or U.K. law). A handful of incorporated consortia are formed as U.S. for-profit limited liability companies (LLCS). Contractual consortia are groups that are defined only by a contractual relationship among participants. Contractual consortia generally become unwieldy as a group grows in size or complexity 
(they cannot open a bank account or own a trademark, for example, forcing awkward work-arounds for these common activities), and arguably create some liability risks for participants (who risk being held liable for actions of the group under partnership legal theories), but some contractual consortia operate for many years.

- Consortia also come in a broad array of flavors, and play a wide variety of roles in the ICT standards setting ecosystem:

- Some large internationally-focused incorporated consortia, such as the World Wide Web Consortium (W3C) or the Internet Engineering Task Force (IETF), differ from large formal SDOs like IEEE or ASTM only in that they have not pursued formal accreditation from a government-sanctioned authority. In practice they look and operate much like large formal SDOs.

- Contractual consortia range from simple relationships among a handful of peer companies focused on developing an early draft specification that can be brought to a more formal body, to sophisticated and complex long term relationships among different tiers of stakeholders, often framed as "Promoters," "Contributors" and "Adopters." USB is a striking example of the latter: the main USB specifications are developed and decided-upon by a small group of Promoter companies, with input from a larger group of Contributor companies, and then are ultimately used by a very large group of Adopter companies. The relationship among these different parties is based on contract.

- As discussed further below, consortia may have complementary or symbiotic relationships with other consortia or with formal SDOs. The USB Promoters Group (a contractual consortia) charges the USB Implementers Forum (an incorporated consortia) with certain tasks related to conformance testing and specification management, for example. The Wi-Fi Alliance (an incorporated consortia) performs marketing and compliance testing services for certain specifications developed by the IEEE (a formal SDO). Occasionally a formal international SDO will reference the work of a consortia, giving the consortia specification the imprimatur of an international standard. ISO referencing certain USB and W3C specifications are notable examples. Also, while not necessarily the kind of organization thought of as standards consortia, patent pool organizers provide another example of a symbiotic relationship: for example, the MPEG-LA organization offers patent licensing options that layer on top of a standards and intellectual property regime created by ISO (a formal SDO).

- The emergence of umbrella consortia is a relatively recent phenomenon. These are non-profit incorporated consortia that host other consortia, under a defined framework. The IEEE Industry Standards and Technology Organization (ISTO) was a pioneer with this model, and currently hosts a mixture of 17 different groups under its 
framework, some separately incorporated and some contractually-based. Similarly, the Linux Foundation has emerged as a leader in this area, hosting over 30 softwarefocused projects under its umbrella (also a mixture of separately incorporated and contractually-based groups). A third, more recent, example is the Joint Development Foundation, which takes a unique approach to legal structure, forming each new group around a new single-member limited liability company (LLC) that is created as a JDF subsidiary.

- In addition to standards created and supported by formal SDOs and consortia, the ICT ecosystem relies on standards promulgated by a single company, called single promoter standards in our taxonomy. Single promoter standards are standards that a company intentionally promotes for adoption by third parties. Widely adopted technologies that are not intentionally promulgated as standards-e.g. Microsoft Windows, or Intel x86-are not included under this taxonomic framework. Rather, this category is intended to capture standards like the 12C standard described above: in that case, Phillips (now NXP) published the specification for wide adoption (in that case with an initial intent, now abandoned, to collect royalties on implementations). Other examples include USB-related host controller specifications freely distributed by Intel or various mechanical socket specifications published by IBM in the early days of the personal computer.

No definitive count of the number of organizations that fall into each category exists. One industry analyst maintains a database of ICT SSOs that includes over 1000 entries. ${ }^{4}$ This author recently performed an informal assessment of a list of approximately 400 currently active ICT SSOs and estimated that about half were formal SDOs and half consortia.

\section{The "open standards" debate.}

The taxonomy described above primarily focuses on the identity of a party creating standards. Another, more contentious approach to categorizing standards setting organizations focuses on the process by which standards are created, and on the associated intellectual property rules. This issue manifests as a debate over whether particular standards are "open."

There is no agreed-upon definition of "open standard." An intrepid Wikipedia editor cataloged over twenty proposed definitions ${ }^{5}$, many of which are mutually exclusive, and the academic literature is replete with different perspectives ${ }^{6}$. Generally, at the risk of oversimplification, the proposed definitions fall into two broad camps: (a) a process-oriented

${ }^{4}$ http://www.consortiuminfo.org/links/linksall.php

${ }^{5}$ https://en.wikipedia.org/wiki/Open_standard

${ }^{6}$ Compare, e.g., Mark Lemley, Intellectual Property Rights and Standard-Setting Organizations, 90 Calif. L. Rev. 1889 (2002) and Nicos L. Tsilas, The Threat to Innovation, Interoperability, and Government Procurement Options From Recently Proposed Definitions of "Open Standards", 10 Int'l J. Comm. L. \& Pol'y 8 (2005). 
definition favored by traditional formal SDOs, and (b) a royalty-free intellectual propertyoriented definition favored by the open source community.

The "OpenStand" principles", set out by a coalition of prominent formal SDOs and several large consortia in 2012, exemplify the process-oriented perspective. They highlight "five fundamental principles of standards development":

- Due process. Decisions are made with equity and fairness among participants. No one party dominates or guides standards development. Standards processes are transparent and opportunities exist to appeal decisions. Processes for periodic standards review and updating are well defined.

- Broad consensus. Processes allow for all views to be considered and addressed, such that agreement can be found across a range of interests.

- Transparency. Standards organizations provide advance public notice of proposed standards development activities, the scope of work to be undertaken, and conditions for participation. Easily accessible records of decisions and the materials used in reaching those decisions are provided. Public comment periods are provided before final standards approval and adoption.

- Balance. Standards activities are not exclusively dominated by any particular person, company or interest group.

- Openness. Standards processes are open to all interested and informed parties.

The royalty free IPR-oriented perspective is exemplified by the Open Source Initiative's definition of open standard, which includes the following requirements:

- Availability: The standard MUST be freely and publicly available (e.g., from a stable web site) under royalty-free terms at reasonable and non-discriminatory cost.

- Patents: All patents essential to implementation of the standard MUST: (a) be licensed under royalty-free terms for unrestricted use, or (b) be covered by a promise of nonassertion when practiced by open source software.

- No Agreements: There MUST NOT be any requirement for execution of a license agreement, NDA, grant, click-through, or any other form of paperwork to deploy conforming implementations of the standard.

Notwithstanding the difficulties associated with defining open standards, there appears to be widespread consensus that open ICT standards are vital. A white paper by an industry trade association stated the point well: "The ideal of open standards is widely accepted, although

\footnotetext{
${ }^{7}$ https://open-stand.org/about-us/principles/
} 
there are different dimensions (and contending definitions) of 'open.'"8 Or, as one academic stated simply: "Open standards ... are becoming increasingly important." 9

The importance of consortia and single promoter standards for ICT.

Standards professionals and policymakers who operate within the world of traditional formal SDOs - particularly the world of national standards bodies, regional organizations, and the "big three" international SDOs - might assume that this world represents the heart of global standard setting. At least as applied to ICT, this assumption would be wrong. Consortia and single promoter standards play a critical role in ICT standardization.

A 2010 study performed by the author of this Chapter, along with several co-authors, demonstrates the point. That study began with a simple question: how many standards are embodied in a modern laptop computer? In the course of answering this question we analyzed the nature of the developer of each identified standard, and the intellectual property regime associated with each standard.

Our study identified 251 interoperability standards embodied in a modern laptop computer. Our count of interoperability standards was not comprehensive: we became aware of some omissions. Accordingly, the count sets only a floor: a modern laptop embodies or utilizes at least 251 interoperability standards, but the actual number is higher.

Of the 251 standards we identified, 112 (44\%) were developed by consortia, and 49 (20\%) were single-promoter standards. Formal SDOs developed 90 (36\%) of the identified standards. In other words: only about one-third of the standards in a 2010-era laptop computer were developed by formal SDOs; the rest were developed by consortia and individual companies.

This theme is consistent with some observations that can be made about a 2014 study of the royalty stack in a smart phone. ${ }^{10}$ The authors of that study did not expressly address the question of the type of standards developer that created the standards that the study authors identify in the course of their analysis, but a reader can count and categorize each. That study explicitly or implicitly references twenty different standards setting organizations. Applying the taxonomy outlined here to these SSOs, we observe that fourteen are consortia and six are formal SDOs. Perhaps coincidentally, we can make an inference similar to the conclusion of the

\footnotetext{
${ }^{8}$ http://cdn.ccianet.org/wp-content/uploads/library/13\%200penStandards-Abstract2010.pdf

${ }^{9}$ Kevin Werbach, Higher Standards Regulation in the Network Age, 23 Harv. J. Law \& Tec 179 (2009).

${ }^{10}$ Armstrong, Ann K. and Mueller, Joseph J. and Syrett, Tim, The Smartphone Royalty Stack: Surveying Royalty Demands for the Components Within Modern Smartphones (May 29, 2014). Available at SSRN: http://ssrn.com/abstract $=2443848$ or http://dx.doi.org/10.2139/ssrn.2443848
} 
2012 laptop study: only about one-third of the standards setting organizations identified in the smartphone study are formal SDOs.

Of course, numbers do not tell the whole story. One could make judgements about the relative importance of different standards: for example, perhaps the wireless voice and data functionality provided by LTE (created by a formal SDO) is more important to a mobile device than functions like the ability to connect to peripheral devices using Bluetooth or to add data storage using an SD Card (both standards created by consortia). It is unclear where this sort of qualitative assessment would ultimately lead on the question of the relative importance of consortia vs. formal SDOs, though. The laptop example in particular presents dozens of examples of consortia and single promoter standards that are essential to the core functions of the device.

The numbers also do not tell the fascinating story of interrelationships between consortia and formal SDOs. Consortia interact with formal SDOs in a number of ways:

- Marketing support. Consortia can explain and market new technologies to consumers. For example, consider the consumer appeal of "Wi-Fi" in contrast to "IEEE 802.11b." One of the the key initial roles of the Wi-Fi Alliance was to promote the technology embodied in IEEE specifications to potential implementers and to the public.

- "Plugfests," compliance testing, and logo licensing. The fact that a specification is approved by a SSO does not automatically lead to interoperable products in the market. Implementers of a standard can interpret inevitable ambiguities differently, and make judgements about how to implement a standard that lead to incompatibilities among specification adopters. Many consortia are targeted at solving this problem as a core part of their mission. This can be accomplished through informal "plugfests" where groups of implementers gather and test interoperability among themselves, or though more formal compliance testing processes. In many cases compliance testing is accompanied by a logo licensing program, where implementers of compliant products are approved to use a certain logo that signifies a compliant implementation. Consortia can apply these processes to their own standards, but in some cases consortia provide this sort of service for standards developed by formal SDOs. WiFi Alliance is a wellknown example here as well: WFA played a critical role driving interoperability testing for the IEEE's 802.11 specifications, rewarding compliant implementations with the right to use the "WiFi" name and logo. It's difficult to overstate the importance of this compliance enforcement role played by consortia, as the existence of a specification alone is generally insufficient to create interoperability in the market, and some kind of compliance testing process is required. Consortia have developed models for addressing this that formal SDOs have generally been unable to replicate, and can thus play an important complementary role for formal SDOs in some cases. Logo licensing represents a remarkable form of industry self-regulation. 
- 'Feeder' specifications. Groups of companies will often create lightweight contractual consortia with the intent of creating an initial draft specification that can be contributed into the established specification development process of a formal SDO.

- The JTC1 PAS process. ISO/IEC JTC 1 has defined a process for the formal adoption of technical specifications from sources outside of JTC 1 as ISO/IEC international standards: the JTC 1 PAS Transposition Process. Under this model, a consortium may put forward some of its publicly available specifications (PAS) to JTC 1 for national body approval. JTC 1 guarantees that the result will not diverge from the consortium's documents without its consent. More than 115 ISO/IEC international standards have been approved through this process. Nine different consortia are approved PAS submitters.

- Other SDO adoption processes. IEC also has a unique relationship with USB that resembles the PAS process, but is not officially part of it. Similarly, other SDOs will occasionally adopt consortia specifications as their own-for example, the Telecommunications Industry Association adopted a specification produced by the consortia HomePlug Alliance as an official TIA standard.

- Incorporation by reference. Consortia and formal SDOs will routinely make arms-length references to specifications developed by other organizations, as part of their own specifications. Under this model, the standard of one organization will state that certain elements of a standard published by a different organization must be adopted in order to fully implement the standard of the first organization.

- Complementary specification development. Consortia and formal SDOs may cooperate to develop complementary specifications. For example, MIPI Alliance (a consortium) and JEDEC (a formal SDO) cooperate under a "liaison agreement" to enable certain MIPI physical interface specifications to work effectively with JEDEC's storage specifications.

- Patent pools. Patent pool organizations, arguably a type of consortia under our framework, can play a symbiotic role with formal SDOs. For example, the now-defunct Open Patent Alliance formed to develop a patent pool associated with the WiMax specifications. The specifications themselves were developed in IEEE. Similarly, the forprofit MPEG-LA coordinates patent pools for various specifications developed by JTC1.

The key point with this analysis is that ICT standardization involves far more than just the established formal SDOs. Consortia play a critical role, both in creating a large number of important standards and in bolstering formal SDOs with important substantive contributions, marketing and compliance testing support, and more. Any understanding ICT standardization requires comprehension of this role.

\section{Many important ICT standards are (arguably) not open standards.}


As noted above, while there is no consensus about what "open standards" really means, there does seem to be a high-level consensus that open standards are important and desirable. This view is understandable, as under any of the proposed definitions various economic and public policy benefits that can potentially flow from open standards seem compelling, and the concept of openness has an intuitive appeal. Enthusiasm for open standards may be tempered by an uncomfortable truth, however: in practice, many important ICT standards are not open standards.

The analysis here is straightforward. Applying the process-oriented definition of open standards, the observation is that while formal SDOs are generally more likely to meet this definition, (a) the majority of ICT standards implemented in real-world devices are created by consortia and single promoters, and (b) while some consortia meet the process-focused definition of open standards, many do not (nor, of course, do single promoter standards). Alternatively, applying the royalty-free IP-oriented definition of open standards, the observation is that the large majority of ICT standards are produced under RAND/FRAND (i.e. not explicitly royalty-free) IP terms.

One challenge in assessing consortia against the process-focused definitions of open standards is that the definitions leave wide latitude for interpretation. A second challenge is that governance models among consortia vary widely, making generalizations difficult. Nonetheless, and again noting the serious risk of oversimplification, the chart below attempts to assess a typical mid-size incorporated consortium (e.g. consortia like the PCI-SIG, FIDO Alliance, NFC Forum or the OpenPower Foundation, and not SDO-like consortia such as the W3C) against the criteria set forth by the "OpenStand" group.

\begin{tabular}{|l|l|}
\hline "OpenStand" criteria: & Met by typical incorporated consortia?: \\
\hline $\begin{array}{l}\text { Due process. } \\
\text { - Decisions are made with equity and fairness } \\
\text { among participants. No one party dominates } \\
\text { or guides standards development. }\end{array}$ & $\begin{array}{l}\text { Arguable. Final decisions are typically made } \\
\text { by a Board of Directors appointed by a small } \\
\text { group of consortia founders. Founders are } \\
\text { - Standards processes are transparent and } \\
\text { opportunities exist to appeal decisions. } \\
\text { - Processes for periodic standards review and } \\
\text { updating are well defined. }\end{array}$ \\
$\begin{array}{l}\text { are made up of companies that can provide } \\
\text { substantial financial support to the consortia. } \\
\text { Directors have fiduciary duties to the } \\
\text { consortia, which may mitigate against undue } \\
\text { founder influence. Transparency of Board } \\
\text { decision-making and standards development } \\
\text { processes varies, and often is limited to } \\
\text { consortia members. }\end{array}$ \\
\hline $\begin{array}{l}\text { Broad consensus. Processes allow for all } \\
\text { views to be considered and addressed, such } \\
\text { that agreement can be found across a range } \\
\text { of interests. }\end{array}$ & $\begin{array}{l}\text { Arguably no. Many consortia are made up } \\
\text { only of interested industry stakeholders. } \\
\text { Consumer representatives, academics or } \\
\text { government representatives may be } \\
\text { ineligible to participate or priced out of }\end{array}$ \\
\hline
\end{tabular}




\begin{tabular}{|c|c|}
\hline & $\begin{array}{l}\text { membership. Some consortia do enable } \\
\text { membership from outside of industry, but } \\
\text { decision-making typically rests with industry } \\
\text { stakeholders. }\end{array}$ \\
\hline $\begin{array}{l}\text { Transparency. } \\
\text { - Standards organizations provide advance } \\
\text { public notice of proposed standards } \\
\text { development activities, the scope of work to } \\
\text { be undertaken, and conditions for } \\
\text { participation. } \\
\text { - Easily accessible records of decisions and } \\
\text { the materials used in reaching those } \\
\text { decisions are provided. } \\
\text { - Public comment periods are provided } \\
\text { before final standards approval and } \\
\text { adoption. }\end{array}$ & $\begin{array}{l}\text { Arguably no. New consortia typically form as } \\
\text { the result of private discussions among } \\
\text { potential founders; no public pre-formation } \\
\text { announcements are made. Supporting } \\
\text { material used by consortia to decide upon } \\
\text { and develop their specifications is not } \\
\text { typically revealed publicly. Consortia } \\
\text { members at certain membership levels have } \\
\text { access to the standards development } \\
\text { process, but typically no public outreach is } \\
\text { made. Final approved specifications may be } \\
\text { available only to members, or may be made } \\
\text { available publicly. }\end{array}$ \\
\hline $\begin{array}{l}\text { Balance. Standards activities are not } \\
\text { exclusively dominated by any particular } \\
\text { person, company or interest group. }\end{array}$ & $\begin{array}{l}\text { Difficult to generalize. In some cases, a strong } \\
\text { industry player may be able to build a } \\
\text { consortium around its particular interests. } \\
\text { More typically, however, a consortium will } \\
\text { have to address a broad set of industry } \\
\text { interests in order to achieve market } \\
\text { acceptance. Consortia may represent } \\
\text { industry segments: e.g., various competing } \\
\text { wireless power consortia represent } \\
\text { groupings of industry players with different } \\
\text { technical and business interests. Non- } \\
\text { industry interests may not be represented, } \\
\text { however. }\end{array}$ \\
\hline $\begin{array}{l}\text { Openness. Standards processes are open to } \\
\text { all interested and informed parties. }\end{array}$ & $\begin{array}{l}\text { Arguable. Once formed, incorporated } \\
\text { consortia are typically open to all interested } \\
\text { industry players, but leadership roles may be } \\
\text { limited to the original founders. }\end{array}$ \\
\hline
\end{tabular}

The analysis set out here is not intended as a value judgement, but rather simply as empirical observation. The reality of ICT standardization is that many standards are created by consortia, and at least some consortia standards are arguably not "open standards" under the process-oriented definition of the term.

Assessing ICT standards against the royalty free IP-oriented definition of open standards involves less ambiguity. In connection with the laptop study described above, we were able to allocate 197 of the 251 standards into one of three broad intellectual property mode 
categories: RAND, royalty free, or patent pool (we lacked sufficient information to categorize the remaining 54 standards). Of the 197 we categorized, 148 (75\%) were RAND, 43 (22\%) were $\mathrm{RF}$, and $6(3 \%)$ utilized a patent pool. The original study lumped SDO and consortia standards together for purposes of this analysis, but a quick assessment of the original data suggests about a $60 \% / 40 \%$ breakdown for consortia alone-that is, about $60 \%$ of the consortia standards with identifiable IP policies were developed under RAND terms, with $40 \%$ developed under royalty free terms. The conclusion here seems clear: if a royalty free IP policy is the defining characteristic of an open standard, then the large majority of ICT standards are not open standards.

The lesson here for policymakers may be that policy preferences for open standards should not be axiomatic. One issue, of course, is that the definitional question around open standards is unsettled. Perhaps more interestingly, the analysis here suggests a tension between idealism and pragmatism. Compelling policy and economic arguments can be mustered in favor of open standards. On the other hand, the current ICT standardization system is built on a complex, diverse network of standards setting organizations, many of which would not be deemed "open" under most definitions. This may be a feature, not a bug: that is, "closed," industry-centric consortia may be able to form and move quickly and respond in innovative ways to market needs in a manner that more established open SSOs cannot. Further, closed consortia may compete against other consortia, with market forces ultimately deciding between alternative approaches to standardization.

Ultimately, however, the main point of this analysis was to simply observe and acknowledge the reality that the current ICT standardization system relies on non-traditional SSOs and standards-i.e., consortia-developed and single promoter standards, often developed via processes that fail to meet any definition of open standards - to a startling high degree. Any understanding of the ICT standards ecosystem requires a comprehension of this full, complex picture, drawing together both the formal SDO system and the consortia models.

\section{New developments: the emergence of open source as an alternative to standards.}

A final observation about the ICT standardization ecosystem is that it is changing rapidly. This is due in part to the "software eating the world" phenomenon identified by Mark Andreesson ${ }^{11}$ : many functions that previously were implemented in hardware are now being implemented in software. Interfaces that previously required detailed hardware-focused specifications are increasingly abstracted away, and implemented now in a layer of software code.

A second factor driving change is frustration with the pace of the standardization system. SSOs, particularly formal SDOs, tend to be slow moving institutions, emphasizing due process and methodical organizational approaches over speed. Industry change seems to be accelerating, however. The traditional PC industry, for example, innovated on cycles measured

11 http://www.wsj.com/articles/SB10001424053111903480904576512250915629460 
in years, while the loT industry is now innovating in cycles measured in months. The need for interoperability is more acute than ever in an loT-centric world, though. Industry demand for interoperability standards is now outpacing the ability of the traditional standards system to deliver.

Open source software has stepped into this breach. Open source development philosophies and methodologies-embodied in the slogan "rough consensus and running code" -enable faster development of solutions than SSOs can typically deliver. Further, software code can work as a solution to interoperability problems and replace solutions that may have required direct hardware interfaces in the past. Companies that perceive a need for interoperability are increasingly turning to open source projects instead of standards development efforts.

The freedom and flexibility enabled by open source licenses creates a challenge for this new open source-focused approach to interoperability. Stakeholders may find that immediately upon the initial conclusion of an open source development project they have an interoperability solution, as all relevant parties adopt that particular code can interoperate. Thereafter, however, each implementer may decide that different features should be added, and each would be free to do so under the applicable license terms (i.e., this sort of freedom is enabled by all open source licenses). Without some defined, canonical version of the code, interoperability soon can break, recreating the initial problem. But managing a canonical version of the code requires a governance process and messy, time-consuming discussions and compromises-i.e., it starts to look much like a traditional SSO.

A second license-related challenge relates to patents. SSOs have developed a sophisticated understanding of how patents potentially apply to standards, and have established models for addressing these patent risks. Open source licenses address patents in different, and sometimes incompatible ways. Reconciling the text of applicable licenses, and the philosophies underlying the text, can be difficult when the worlds of SSOs and of open source code collide.

The story of standards in 2017 and beyond may be development of new methodologies and institutions that can harness the best of the traditional standards development world and incorporate the speed and agility of open source development processes. The need for ICT products and services to interoperate is not going away. Precisely how this interoperability will be effectuated is a key open question.

\section{Conclusion}

The main point of this Chapter was to provide a framework for understanding the extraordinarily complex system of standards setting organizations in the information and communications technology industry. Formal standards development organizations are a key element, but far from the whole story. Consortia play a fundamentally important role, both in creating standards and in providing services that complement the standards-setting efforts of 
formal SDOs. Standards propagated by single companies also play a surprisingly important role. "Open" standards, intuitively appealing, prove difficult to define and are perhaps less important to the overall standards ecosystem that one might expect. Technical change is putting the entire standardization system under stress, and we are beginning to see new models emerge to address the ongoing critical challenge of how to facilitate interoperability of products and services within a deeply interconnected ICT ecosystem. 